\title{
Guest editorial: Five steps towards exploring the future of operations management
}

\author{
Jan Holmström • A. Georges L. Romme
}

Received: 21 November 2011 /Revised: 3 December 2011 / Accepted: 5 December 2011 /Published online: 9 February 2012

(C) The Author(s) 2012. This article is published with open access at Springerlink.com

Keywords Exploration · Technology OM Practice · Design principles

\section{Introduction}

Operations Management Research was started to promote research that advances both the theory and practice of operations management (Meredith and McMullen 2008). In this guest editorial, we discuss how operations management $(\mathrm{OM})$ researchers could more systematically engage in the exploration of technological opportunity. In this respect, operations management research is an activity shaped by technological invention and innovation in use. Whereas OM researchers currently are still mainly interested in the performance of $\mathrm{OM}$ processes and practices adopted by large populations (e.g. of firms or customers), they should also attend to early adopters trying out new technology as well as those combining and configuring existing technologies in new ways. Expanding attention from studying how established practice transforms operational contexts in terms of efficiency and reliability to the development of innovative practice requires an integrative methodological approach for

\section{J. Holmström}

Industrial Engineering and Management, Aalto University, P.O. Box 15500, FI-00076 Aalto, Finland

e-mail: jan.holmstrom@aalto.fi

A. G. L. Romme $(\bowtie)$

School of Industrial Engineering,

Eindhoven University of Technology,

P.O. Box 513, 5600 MB Eindhoven, Netherlands

e-mail: a.g.1.romme@tue.nl
OM research. We outline such an integrative approach, based on a science-for-design approach. To systematically link practice and science, five methodological steps for the systematic formulation of research agendas and the development and testing of design principles are proposed. As such, we provide a framework that effectively connects practice and the scientific knowledge base in developing field-tested and grounded OM knowledge.

\section{Practitioners leading in basic OM research and innovation}

In most disciplines, academic researchers engage in basic research (with a long time horizon) towards future technologies, whereas practitioners focus on the application and continuous improvement of existing technologies. In operations management $(\mathrm{OM})$ these roles are actually reversed (Holmström et al. 2009): practitioners do most of the activities that can be regarded as basic research, such as figuring out where and how novel technologies can be introduced to get operational benefits, and how novel technologies can be combined with existing operational practices in novel combinations. The academic OM researcher attempts to theoretically capture and explain the outcomes of practitioners' work, once technologies and practices have become widespread and fully institutionalized.

Unless the academic OM discipline addresses this issue at a time in which technologies become more open and combinatorial, the time lag between the leading edge of practice and insightful research in $\mathrm{OM}$ is likely to grow, thus decreasing the practical value of academic research. An example is the potential effects and benefits of adopting social media (e.g. Chatter, Twitter, Facebook, YouTube), 
and more broadly web 2.0 infrastructures, in operational processes in the area of customer and field services as well as new product development. Many firms, such as Dell and Cisco, are doing pioneering work in this area. For example, Dell has recently released Chatter to its entire work force (over $100 \mathrm{~K}$ employees). Other emerging technologies with the potential to radically change OM practice are additive manufacturing and unique product identification.

OM researchers are not at the forefront of these technological innovations, and as such universities and academic research centers are no longer the primary knowledge producers in the OM field (cf. Romme 2003). Today, management consulting firms (e.g. McKinsey) and service providers (e.g. IBM) are systematically creating knowledge on the effects of introducing new technology in operations management, while academic institutions tend to discourage individuals interested in newness and design (Baldwin and Clark 2000; Birkinshaw et al. 2008). Moreover, researchers, reviewers and editors lack the means for conceptualizing and evaluating research into emerging $\mathrm{OM}$ practices that arise from novel technologies (Holmström et al. 2009). We argue operations management research may systematically engage in exploring newness (cf. Hayes et al. 2005; Holmström et al. 2009), in addition to modeling and explaining improvement of operational processes in terms of for example reliability, efficiency, flexibility and sustainability. As such, we outline five steps in shifting research from a predominant orientation on explanation to a broader orientation, also including exploration.

\section{Five steps towards exploration of newness in OM research}

To outline how a researcher can introduce elements of exploration to academic OM research, we first briefly describe our position on the relation between evolution of technology and OM practice, and then propose five steps that outline how OM researchers can support practitioners by developing design principles and research agendas which synthesize the existing body of knowledge as well as develop forward-looking design principles.

3.1 Operations management research and the role of new technology

If we define 'technology' as a means to fulfill a human purpose (Arthur 2009), then OM techniques, methods and tools can be considered to be technologies (in a broader sense). In this respect, the technology development literature has traditionally considered technology as something largely self-sufficient and fixed in structure, and subject to occasional innovations (e.g. Basalla 1988). More recently, Arthur (2009: 25) has argued that modern technology is not just a collection of independent means of production, but "is becoming an open language for the creation of structures and functions in the economy. Slowly, at a pace measured in decades, we are shifting from technologies that produced fixed physical outputs to technologies whose main character is that they can be combined and configured endlessly for fresh purposes."

Figure 1, adapted from Kelly (2010), visualizes the evolution of radical technological innovation from a mere idea of the possibility as such to a transforming force in its contexts of use. From this perspective, addressing the problems of invention and innovation in use are two intimately linked waves of activity. The first stage is creative and deals with a design problem, while the second stage deals with the management challenges related to the positive as well as potentially destructive effects of inventions in their different contexts of use. The transition from invention of technology to innovation in use offers many opportunities for proactive and explorative OM research.
Fig. 1 Two stage model of invention and innovation in use (adapted from Kelly 2010: 142)

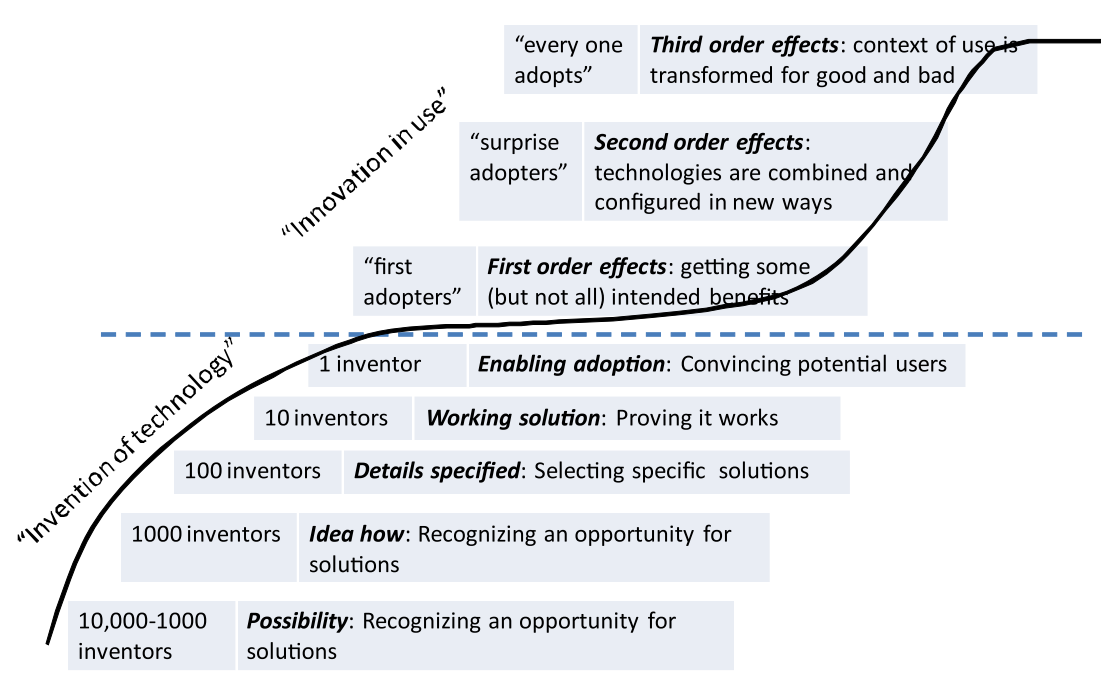


The effects of radical technological innovations (e.g. computers, wireless communication, additive manufacturing) take time to be translated in widely used products and processes, but many of these effects can be anticipated, described and theoretically analyzed much earlier. For example, at the time both practitioners and academics recognized (some of) the first order effects of using computers to integrate activities within the firm and between firms (cf. Magee 1958). Moreover, some OM researchers work proactively with industry on second order effects - for example, computing being combined in new ways with other innovations (e.g. business process management combining IT and business process modeling) (Davenport and Short 1990). Similarly, academics would be able to work with practice on the third order effects of introducing IT everywhere in the operations of a business - for example, material flows and resources that are continuously monitored and controlled over the entire life-cycle and also across organizationsbefore the fact (e.g. Meyer et al. 2009).

Today, OM practitioners are facing many challenging second and third order effects of technology previously adopted, such as the emergence of global supply chains and markets enabled by the adoption of standardized parts; or the emergence of performance-based logistics in aerospace and defense drawing on the widespread adoption of IT technology in maintenance and use. It is especially in such situations that practitioners turn to academic OM research for support (e.g. De Kok et al. 2005; Kranenburg and Van Houtum 2009). However, without a strong foundation in research focusing on the effects of the initial adoption of new technology, as well as the generating mechanisms of such first and second order effects, it is difficult to understand how new technology may change the operational performance of organizations. This leads to the first step towards exploring newness in $\mathrm{OM}$ research:

Step 1 OM involves creating, designing and coordinating business operations that serve to develop and produce goods and/or services using the best available means from a growing and continually changing stock of technologies. As such, OM researchers need to recognize the differences between understanding, analyzing and modeling first-, second- as well as third-order effects of new technology:

- First-order effect: operational outcomes achieved by early adopters trying out new technology;

- Second-order effect: operational outcomes achieved by adopters combining and configuring this technology in new ways;

- Third-order effect: the impact on operations in different contexts of use, when large populations (e.g. of firms or customers) are using the technology.

\subsection{Dealing with'newness' in $\mathrm{OM}$}

Considering that new technologies with potential relevance for OM are continually emerging, what is the type of questions that researchers should consider now, in order to be relevant once practical experimentation commences and adoption rates start increasing? As such, we argue that OM researchers need to develop research agendas that (a) serve to develop robust theories that adequately describe and explain $\mathrm{OM}$ as an empirical phenomenon and (b) systematically connect these theories to practice, by creating instrumental knowledge that informs OM practitioners.

The core mission of any science for design is to develop general knowledge that professionals can draw on to design (pathways towards) solutions to their specific challenges and problems (Van Aken 2004). This implies that science, design and practice are three highly different but complementary modes of developing knowledge and expertise that ideally inform, reinforce and build upon each other (see Fig. 2). For the OM researcher, the design mode opens up a potentially new role in exploring newness and actively supporting leading edge practice.

Thus, we offer:

Step 2 Because emerging technologies create opportunities towards new ways to operate, OM researchers need an integrative research agenda that includes creation, design and construction in addition to description, modeling and explanation as key activities in the design-practice-science cycle of operations management.

\subsection{Heuristics for supporting the exploration of future} practice

Whereas the typical outcome of OM research is the empirically validated hypothesis or model, the main research product of design research is a well-tested (set of) heuristic(s) for designing and constructing and using particular artifacts, such as inventory management systems. These heuristics are captured in so-called design principles, also known as design propositions or design rules (Romme 2003). Design principles refer to generic actions to address a generic problem or challenge, and can be deliberately created from research findings, but may also initially emerge from practice (Romme and Endenburg 2006). Examples of the former are Kranenburg and Van Houtum's (2009) work on improving spare parts planning at ASML, and the development of an advanced planning and scheduling system at Philips by De Kok et al. (2005). An example of design principles emerging from practice is the case of Just-in-Time production which, through systematic efforts to study JIT and related practices in the automotive 
Fig. 2 Design-practice-science cycle

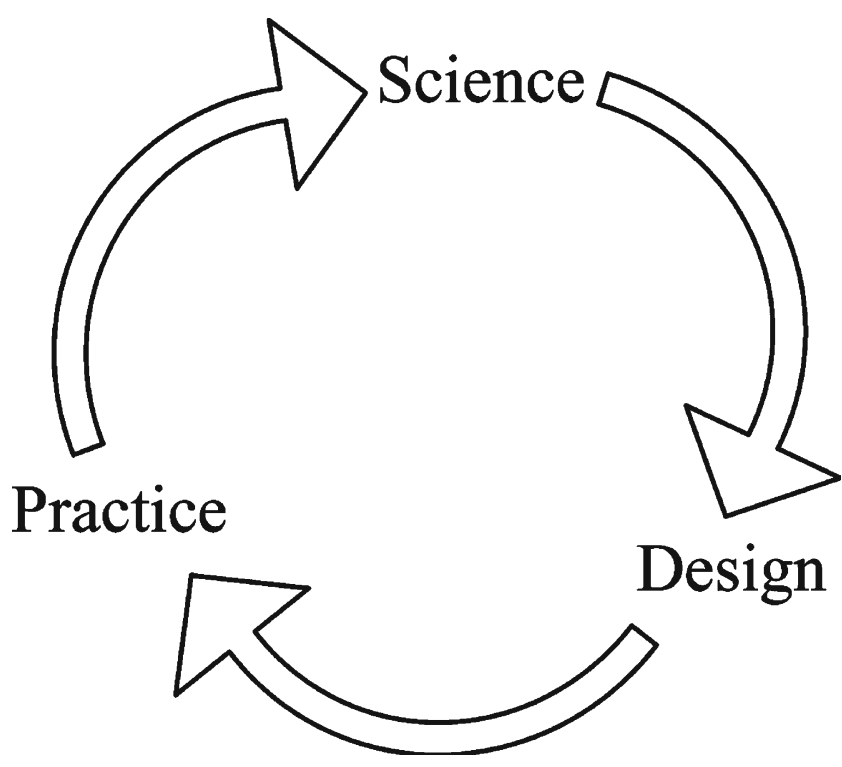

industry, led to the articulation of lean manufacturing principles (Womack et al. 1991).

Fully developed design principles specify "what to do, in which situation, to produce what effect and offer some understanding of why this happens" (Denyer et al. 2008: 396). These design principles are not descriptions of the solution itself, but serve to guide the construction of detailed solutions in particular settings. As such, design principles connect the scientific and the practical in the ongoing design-practicescience OM research cycle (cf. Figure 2). Denyer et al. (2008) suggest design principles are composed of four related aspects. Accordingly, design principles in OM can be formulated in a CAGO format: the specific Context, the (set of) Action(s), and the Generative mechanisms through which the action is likely to produce particular Outcomes. This format serves to situate and contextualize the action and incorporates the causality between actions and outcomes, while acknowledging the importance of understanding the underlying generative factors and processes. As such, design principles are essential in connecting explanatory knowledge (science) to design and construction processes in practical settings:

Step 3 Adopt the notion of design principles, to connect description-modeling-explanation and creationdesign-construction in the OM research cycle. Design principles in a CAGO-format refer to the particular Context, the (set of) Action(s) to be taken, and the Generative mechanisms through which the action is likely to produce particular Outcomes.

\subsection{Seeking out the future of practice}

Design principles can be useful in two ways: for problem solving and solution spotting (Holmström et al. 2009). In problem solving, a user is typically trying to find a better way of achieving particular goals, whereas in solution spotting a technology provider identifies a way to use a particular technology for achieving some goal in a new context. Adoption of a technology is most likely to take off when solution spotters correctly identify problems that many potential users seek to solve. This is in essence the co-creation of value at the heart of complex service businesses, such as power by the hour, software as a service, and performance-based logistics.

Reliability is a central OM objective alongside efficiency, flexibility and responsiveness. Design principles in OM would, for example, serve to improve reliability of inventory management. A systematic review that synthesizes the body of knowledge using the CAGO-structure can demonstrate for what contexts there are articulated courses of actions, as well as evidence and understanding of the generative mechanisms leading to high reliability.

However, in some contexts inventory management can potentially be handled more efficiently and reliably using novel technologies, in ways not yet described in the existing literature. The CAGO-structure is also a potential tool for such situations. Consider how in a spare parts supply chain, additive manufacturing (i.e. rapid manufacturing, 3D printing) capacity can substitute for inventory (Holmström et al. 2010a). Makebot, a maker of 3D printers, even turns to its 
customers as suppliers of production parts when inventory runs out (von Hippel 2011). Inventory management in more conventional settings, such as project delivery, can also become much more efficient using tracking-based dwell times alerts (Holmström et al. 2011). In such situations, the CAGOstructure serves to formulate and articulate novel propositions, as well as outline directions of further research:

Step 4 To be prepared when OM practitioners start exploring, testing and applying new technologies in novel ways in particular contexts, OM researchers can pro-actively and systematically develop (CAGO formatted) design principles that serve to (a) synthesize the existing body of knowledge as well as (b) develop forward looking research agendas.

An example of using design principles to synthesize and develop a proactive agenda for research can be found in Holmström et al. (2010b)

\subsection{Evaluating design principles}

Design principles, as the embodiment of actionable knowledge, can be created from a variety of sources-for example, from rigorous OM research, narratives on benchmark practices, or consulting experiences. However, design principles need to be(come) grounded in research and tested in practice (Romme 2003). That is, the ideal and most robust design principle is firmly grounded in the scholarly body of knowledge available in the literature as well as extensively tested in practice.

The extent to which design principles have been tested in practice can be evaluated in terms of their validation by practitioners, that is, their pragmatic validity (Worren et al. 2002). The notion of 'testing' here refers to the common sense notion of field-testing (e.g., trying out whether it works), rather than the more restrictive notion of statistical testing. Scholarly work that deliberately engages in this type of practical testing is rare in the management sciences, and is best done in the context of practitioner-academic collaboration. Practitioner-academic teams seek to jointly interpret the experiences of the practitioners, who are continually looking for ideas and guidelines that can inform their work in practice (Mohrman et al. 2001; Guide and Van Wassenhove 2007).

The role of evidence is pivotal for closing the designpractice-science cycle of OM research:

Step 5 Preferably connect OM practice to the scientific knowledge base by way of field-tested and grounded design principles: that is, the actionoutcome relationship in a design principle is extensively tested and applied in relevant practical contexts, as well as grounded in robust theory regarding the generative mechanisms explaining this relationship.

\section{Discussion}

OM research today almost exclusively focuses on the 'exploitation' side of business operations, such as improving efficiency, reliability and responsiveness. In terms of March's (1991) distinction between exploration and exploitation, this undermines the capability of OM researchers to anticipate and respond to technological and other breakthroughs affecting OM practice. To address the challenge, we argue that 'design' needs to be acknowledged as a key step in the OM research cycle, complementary to practice and science. As such, we advocate a science-for-design approach in which design principles (grounded in scholarly findings and tested in practice) serve to connect OM practice and academia. The systematic adoption and development of design principles gives OM researchers the opportunity to support practice in two ways: through synthesis of available evidence and through proactively developing design principles ripe for exploration in practice.

Open Access This article is distributed under the terms of the Creative Commons Attribution Noncommercial License which permits any noncommercial use, distribution, and reproduction in any medium, provided the original author(s) and source are credited.

\section{References}

Arthur WB (2009) The Nature of Technology: What It Is and How It Evolves. Penguin, London, UK

Baldwin CY, Clark KB (2000) Design Rules, 1: The Power of Modularity. MIT Press, Cambridge, USA

Basalla G (1988) The Evolution of Technology. Cambridge University Press, Cambridge, UK

Birkinshaw J, Hamel G, Mol MJ (2008) Management innovation. Acad Manag Rev 33:825-845

Davenport TH, Short JE (1990) The new industrial engineering: information technology and business process redesign. MIT Sloan Management Review 31:11-27

De Kok T, Janssen F, Van Doremalen J, Van Wachem E, Clerkx M, Peeters W (2005) Philips Electronics synchronizes its supply chain to end the bullwhip effect. Interfaces 35(1):37-48

Denyer D, Tranfield D, Van Aken JE (2008) Developing design propositions through research synthesis. Organ Stud 29:393-413

Guide D, Van Wassenhove L (2007) Dancing with the devil: partnering with industry but publishing in academia. Decis Sci 38:531-546

Hayes RH, Pisano GP, Upton DM, Wheelwright SC (2005) Operations, Strategy, and Technology: Pursuing the Competitive Edge. Wiley, New York

Holmström J, Ketokivi M, Hameri AP (2009) Bridging practice and theory: A design science approach. Decis Sci 40:65-87

Holmström J, Partanen J, Tuomi J, Walter M (2010a) Rapid manufacturing in the spare parts supply chain. J Manuf Technol Manag 21:687-697 
Holmström J, Främling K, Ala-Risku T (2010b) The uses of tracking in operations management: synthesis of a research program. Int $\mathrm{J}$ Prod Econ 126:267-275

Holmström J, Tenhiälä A, Kärkkäinen M (2011) Item dwell time in project inventories: a field experiment. Comput Ind 62:99-106

Kelly K (2010) What Technology Wants. Viking, New York

Kranenburg AA, Van Houtum GJ (2009) A new partial pooling structure for spare parts networks. Eur J Oper Res 199:908921

Magee JF (1958) Production Planning and Inventory Control. New York, McGraw-Hill, 2nd edition

March JG (1991) Exploration and exploitation in organizational learning. Organ Sci 2:71-87

Meredith JR, McMullen PR (2008) Editorial: introducing Operations Management Research: advancing practice through theory. Oper Manag Res 1:1-5

Meyer G, Främling K, Holmström J (2009) Intelligent products: a survey. Comput Ind 60:137-148
Mohrman SA, Gibson CB, Mohrman AMJ (2001) Doing research that is useful to practice: A model and empirical exploration. Acad Manag J 44:357-375

Romme AGL (2003) Making a difference: organization as design. Organ Sci 14:558-573

Romme AGL, Endenburg G (2006) Construction principles and design rules in the case of circular design. Organ Sci 17:287-29

Van Aken JE (2004) Management research based on the paradigm of the design sciences: the quest for field-tested and grounded technological rules. J Manag Stud 41:219-246

von Hippel E (2011) The Paradigm Shift from Producer to User and Open Innovation, Plenary speech, Decision Sciences Institute 42nd Annual Meeting, Boston November 19-22 2011

Womack JP, Jones DT, Roos D (1991) The Machine that Changed the World. Harper-Perennial, New York

Worren NA, Moore K, Elliott R (2002) When theories become tools: Toward a framework for pragmatic validity. Human Relations $55: 1227-1250$ 